\section{Analysis of Genomic DNA Methylation in Six Tissues of the Greater Horseshoe Bat (Rhinolophus ferrumequinum)}

\author{
Sen Liu ${ }^{1,2}$, Yue Zhu ${ }^{2}$, Haixia Leng ${ }^{2}$, Ying Wang ${ }^{1}$, Xiangju Yin ${ }^{1}$ and Yajun Zhao ${ }^{1 *}$ \\ ${ }^{1}$ Institute of Resources and Environment, Henan Polytechnic University, Jiaozuo \\ 454000, Henan, China \\ ${ }^{2}$ Jilin Key Laboratory of Animal Resource Conservation and Utilization, Northeast \\ Normal University, Changchun 130024, Jilin, China.
}

Sen Liu and Yue Zhu have made equal contribution.

\begin{abstract}
A B S T RA C T
DNA methylation may play a vital role in tissue development and differentiation as it plays an important role in gene expression regulation. In previous studies, epigenetic variation in the muscles of bat populations were explored; however, the extent of the patterns and levels of genomic DNA methylation among tissues in chiropteran animals have yet to be investigated. In this study, the epigenetic variation of six tissues in normal state Rhinolophus ferrumequinum (i.e., no pregnancy, nursing, or hibernation) was explored using the F-MSAP technique, including brown adipose tissue (BAT), brain (B), heart $(\mathrm{H})$, kidney (K), liver (L), and muscle (M) tissues. An average of 67.0\% CCGG loci was methylated in each tissue. There were significant methylation differences among tissues in full-methylation $(p<0.001)$ and total methylation $(p=0.001)$. Moreover, various unique methylated loci (15-59) were also detected. Non-negligible level of hemi-methylation $(31.4 \%)$ existed, indicating that CHG methylation may also play a potential role in tissue development and differentiation in $R$. ferrumequinum. BAT and B had different methylation profiles compared to the other four tissues, but the underlying mechanism for this requires further investigation. This work provides basic data for future studies on the intrinsic epigenetic mechanisms of vital biological processes, such as tissue development and differentiation, hibernating processes, and the environmental adaptability of Chiropteran animals.
\end{abstract}

Article Information
Received 29 November 2019
Revised 13 May 2020
Accepted 24 September 2020
Available online 11 October 2021
Authors' Contribution
YZ designed and supported this study.
HL, YW and XY collected tissues and
conducted the F-MSAP assays. SL and
YZ conducted the data analyses and
wrote the manuscript.
Key words
Epigenetic variation, Bats, Chiroptera,
F-MSAP, CHG methylation

\section{INTRODUCTION}

$\mathrm{D}$ NA methylation, one of epigenetic modifications, usually refers to the methylation of the fifth carbon of cytosine in $\mathrm{CpG}$ dinucleotides (i.e., 5-methylcytosine $\left.\left({ }^{5 \mathrm{~m}} \mathrm{C}\right)\right)$. In mammals, most methyl groups are erased in preimplantation embryos and re-established in implantation embryos (Cedar and Bergman, 2012). DNA methyltransferases (DNMTs) are key enzymes involved in establishing and maintaining DNA methylation. In detail, DNMT3a and DNMT3b establish new DNA methylation by adding a methyl group to an unmethylated cytosine in CpGs (i.e., de novo DNA methylation). DNMT1 recognizes and binds these hemi-methylated $\mathrm{CpGs}$ at the replicating forks and methylate the daughter strand during DNA replication (i.e., maintenance) (Lyko, 2018). ${ }^{5 \mathrm{~m}} \mathrm{C}$, especially the methylation at $\mathrm{CpG}$ islands (CGIs), often regulates gene expression by repressing transcription

\footnotetext{
Corresponding author: yakzhao126@126.com 0030-9923/2021/0006-2313 \$ 9.00/0

Copyright 2021 Zoological Society of Pakistan
}

processes (Jones, 2012). In one respect, DNA methylation prevents the binding between promoters and some transcription factors, which are sensitive to $\mathrm{CpG}$ methylation (Greenberg and Bourc'his, 2019). In another respect, DNA-methylated sequences are recognized and bound by methyl $\mathrm{CpG}$ binding domain proteins (MBDs) and transcription repressors, including histone deacetylases (HDACs) and several zinc finger proteins, resulting in gene silence (Jones and Takai, 2001). Therefore, due to the ability of regulating gene expression, DNA methylation plays an important role in vital biological processes of eukaryotes (Klose and Bird, 2006), such as development (Greenberg and Bourc'his, 2019), immunity (MoralesNebreda et al., 2019), and senescence (Horvath and Raj, 2018).

Studies on DNA methylation in animals tend to focus on the pathogenesis and cure of various diseases (Michalak et al., 2019; Schulze et al., 2019). Recent works have extended to domestication, transgenerational inheritance, and the environmental adaptability of wild animals, such as differentially methylated loci that exist between the domestic dog and gray wolf (Banlaki et 
al., 2017), and between Creole cattle and their Iberian ancestors (Sevane et al., 2019). In male wild guinea pigs, various paternal diets induce transgenerational epigenetic modifications (Weyrich et al., 2018). Differentially methylated regions (DMRs) of the genome exist between complete and low lateral plate morphs of three-spine sticklebacks, which possess various phenotypes that may be a result of the number of natural predators (Smith et al., 2015). Notably, most previous studies have investigated one type of tissue at the same state. However, tissuespecific differentially methylated regions (TDMs) exist (Song et al., 2005), meaning that the levels and patterns of DNA methylation vary in different tissues, which may be correlated with tissue-specific gene expression (Reizel et al., 2018). Therefore, exploring the patterns and levels of DNA methylation in various tissues could facilitate the investigation of the relationship between tissue-specific methylation and gene expression, as well as the correlation among different functional states of the same tissue. Only a few studies have investigated the patterns and levels of genomic DNA methylation in various tissues in animals, including Zhikong scallop (Chlamys farreri) (Sun et al., 2014), swine strain Laiwu (Yang et al., 2011), and sika deer (Cervus nippon) (Yang et al., 2018).

In most of these studies, the methylation-sensitive amplified polymorphism (MSAP), or fluorescencelabeled MSAP (F-MSAP) technique was utilized to detect the patterns and levels of DNA methylation. MSAP, the modification of amplification fragment length polymorphism (AFLP) technique (Vos et al., 1995), uses two different DNA methylation-sensitive restriction isoschizomer enzymes $\mathrm{Hpa}$ II and Msp I to detect the methylation state of Cs of 5'-CCGG-3' sites. Because $H p a$ II cleaves the hemi-methylated external Cs and Msp I cleaves full methylated internal Cs in 5'-CCGG-3' sites, MSAP technique explores the information of $\mathrm{CHG}$ and $\mathrm{CpG}$ methylation. In addition, this technique provides massive methylated or non-methylated loci of several individuals concurrently without genomic information (Bossdorf et al., 2008), indicating that it efficiently detects methylation differentiation in non-model species (Schrey et al., 2013). Compared to traditional MSAP, F-MSAP is more sensitive and effective for obtaining epigenetic information using fluorescently labeled primers and capillary gel electrophoresis.

Many studies found that various survival environments could induce change in DNA methylation in both plants and animals (Hu and Barrett, 2017; Huang et al., 2017; Thiebaut et al., 2019). Bats are considered as the bioindicators because their sensitive to climate change and habitat deterioration (Jones et al., 2009), and thus environmental changes may induce their epigenetic variance. In previous studies, the epigenetic variation in muscles among bat populations were explored using MSAP (Liu et al., 2012). However, the extent of DNA methylation variation among tissues in bats is still unknown. In this study, the F-MSAP technique was used to explore the methylation patterns and levels in six tissues of the greater horseshoe bat (Rhinolophus ferrumequinum) in a normal state (i.e., no pregnancy, nursing, or hibernation). This work will address and enhance our understanding of the intrinsic epigenetic mechanisms of tissue development and differentiation, hibernating processes, and environmental adaptability of chiropteran animals and provided basic data for future studies.

\section{MATERIALS AND METHODS}

\section{Ethics statement and tissue sampling}

Six adult bats $(3 \overbrace{}^{\lambda}$ and 3 웅 were collected in an artificial canal in Jiyuan City, Henan Province in China during September 2017. Six tissues from each individual, including brown adipose tissue (BAT), brain (B), heart $(\mathrm{H})$, kidney $(\mathrm{K})$, liver $(\mathrm{L})$, and muscle $(\mathrm{M})$, were collected and frozen in liquid nitrogen. Genomic DNA of each tissue was extracted by a genome DNA extraction kit (SK1205, Shanghai Sangon Biological Engineering Technology and Services Co., Ltd.). Animal experiments were conducted in accordance with the National Animal Research Authority of Northeast Normal University, China (approval number: NENU-20080416).

\section{F-MSAP assay}

About $20 \mathrm{mg}$ of each tissue were ground into powder using liquid nitrogen. Genomic DNA was extracted by a UNIQ-10 column animal genome DNA extraction kit (SK1205, Shanghai Sangon Biological Engineering Technology and Services Co., Ltd.). The quality of DNA was verified by $1 \%$ agarose gel electrophoresis. All DNA samples were adjusted to $200 \mathrm{ng} / \mu \mathrm{L}$ and stored at $-20^{\circ} \mathrm{C}$. The F-MSAP technique using 5'-FAM labeled primers was employed to detect the methylation levels of each tissue sample. F-MSAP uses the isoschizomer enzymes, $\mathrm{Hpa}$ II and $M s p$ I, to detect the methylation state of Cs in 5'CCGG-3' sites. The procedures for F-MSAP, including DNA digestion, ligation, pre-amplified PCR and selective PCR, are described below.

Two copies of genomic DNA from each sample were digested with $E c o$ R I/Hpa II and $E c o$ R I/Msp I at $37^{\circ} \mathrm{C}$ for $4 \mathrm{~h}$. The digestion solution $(20 \mu \mathrm{L})$ contained $5 \mathrm{U} E c o \mathrm{R} \mathrm{I}$, $5 \mathrm{U}$ Hpa II (or Msp I), $2 \mu \mathrm{L} 10 \times$ T4 Buffer, 200 ng DNA template, and deionized water. Then, all DNA fragments were ligated to adapters overnight at $16^{\circ} \mathrm{C}$. The sequences of adapters were in accordance with Xu et al. (2000). The 
ligation solution $(25 \mu \mathrm{L})$ contained digestion products with $5 \mathrm{pmol} E c o$ R I adapter, $50 \mathrm{pmol} H p a \mathrm{II} / \mathrm{Msp}$ I adapter, 1.5 U T4 DNA ligase, $2.5 \mu \mathrm{L} 10 \times$ T4 buffer, and deionized water.

Pre-amplification PCR was a necessary for the preliminary selection and enrichment of ligated DNA fragments. It contained $2 \mu \mathrm{L}$ digestion-ligation product, 2 $\mu \mathrm{L} 10 \times$ PCR buffer, $1.5 \mu \mathrm{L}$ dNTPs $(2.5 \mathrm{mM}$ each $), 0.5 \mu \mathrm{L}$ primer E+A (5'-GACTGCGTACCAATTCA-3') (10 $\mu \mathrm{M})$, $0.5 \mu \mathrm{L}$ primer HM+T (5'-GATGAGTCTAGAACGGT-3') $(10 \mu \mathrm{M}), 1 \mathrm{U}$ Taq polymerase, and $18.3 \mu \mathrm{L}$ deionized water. The PCR conditions were as follows: Predenaturation at $94^{\circ} \mathrm{C}$ for $5 \mathrm{~min} ; 35$ cycles at $94^{\circ} \mathrm{C}$ for $20 \mathrm{~s} ; 56^{\circ} \mathrm{C}$ for 20 $\mathrm{s} ; 72^{\circ} \mathrm{C}$ for $40 \mathrm{~s}$; and a final extension at $72^{\circ} \mathrm{C}$ for $7 \mathrm{~min}$.

Selective amplification PCR further amplified the selective primer pair-specific fragments from PCR products from the previous step. The reaction solution $(25 \mu \mathrm{L})$ contained $1 \mu \mathrm{L} 20$ times diluted pre-amplification product, $2 \mu \mathrm{L} 10 \times$ PCR Buffer, $1.5 \mu \mathrm{L}$ dNTPs (2.5 mM each), 1 $\mu \mathrm{L}$ primer $\mathrm{E}+\mathrm{AXX}(10 \mu \mathrm{M}), 1 \mu \mathrm{L}$ primer $\mathrm{HM}+\mathrm{TXX}(5$ ' FAM labeled) $(10 \mu \mathrm{M}), 1 \mathrm{U}$ Taq polymerase, and $18.3 \mu \mathrm{L}$ deionized water. The PCR conditions were as follows: predenaturation at $94^{\circ} \mathrm{C}$ for $5 \mathrm{~min} ; 13$ touch-down cycles at $94^{\circ} \mathrm{C}$ for $20 \mathrm{~s} ; 65^{\circ} \mathrm{C}$ (reduced by $0.7^{\circ} \mathrm{C}$ in each cycle) for $20 \mathrm{~s} ; 72^{\circ} \mathrm{C}$ for $40 \mathrm{~s} ; 23$ cycles at $94^{\circ} \mathrm{C}$ for $10 \mathrm{~s} ; 56^{\circ} \mathrm{C}$ for 10 $\mathrm{s} ; 72^{\circ} \mathrm{C}$ for $20 \mathrm{~s}$; and a final extension at $72^{\circ} \mathrm{C}$ for $7 \mathrm{~min}$. The selective amplification PCR products were analyzed by capillary electrophoresis. Genemarker v2.2.0 software was used to detect the fluorescent signals at different intensities and locations relative to the GS500 standard.

\section{Statistical analyses}

F-MSAP uses the isoschizomer enzymes, Hpa II, which cleaves the hemi-methylated external cytosine nucleotide when the external cytosine on one strand is methylated (referred to as hemi-methylation), and $M s p \mathrm{I}$, which cleaves full methylated internal Cs (referred to as full-methylation), to detect the methylation state of Cs in 5'-CCGG-3' sites. Four patterns were used for comparing the amplification products from Hpa II and Msp I (bands were scored ' + ' as present and '-' as absent). Type I: +/+, non-methylated; Type II: +/-, hemi-methylation; Type III: $-/+$, full-methylation; Type IV: -/-, uninformative due to hypermethylation or the absence of a fragment (Liu et al., 2012). Methylation levels were calculated using the following formulas:

Hemi-methylation level $=$ II $/(\mathrm{I}+\mathrm{II}+\mathrm{III}) \times 100 \%$,

Full-methylation level $=$ III $/(\mathrm{I}+\mathrm{II}+\mathrm{III}) \times 100 \%$,

Total methylation level $=(\mathrm{II}+\mathrm{III}) /(\mathrm{I}+\mathrm{II}+\mathrm{III}) \times 100 \%$

The msap program in $\mathrm{R}$ software was used to obtain an epigenetic binary matrix (methylation-susceptible loci, including types II and III) from the F-MSAP raw data based on the error rate-based threshold (ERT) at 5\% (Perez-Figueroa, 2013). The 'Mixed Scoring 2' approach of MSAP_calc was used to calculate the number of unique loci of both methylation patterns in each tissue (Schulz et al., 2013). ANOVA was used to estimate significant differences of methylation levels among different tissues $(p<0.05)$.

Nei's unbiased distance based on the epigenetic binary matrix was calculated to estimate the epigenetic differentiation among tissues. Additionally, multivariate analyses were used to further explore the potential relationship among tissues based on methylated loci. The Between-Group Eigen Analysis (Parisod and Christin, 2008) using ADE-4 software was employed to group individual PCA scores of each tissue (PCA in the covariance matrix was based on the epigenetic binary matrix) by maximizing the between-group variance (Thioulouse et al., 1997). Statistical significance was assessed by the Romesburg randomization test $\left(10^{4}\right.$ permutations $)$.

\section{RESULTS}

To explore the patterns and levels of global DNA methylation in $R$. ferrumequinum, genomic DNA methylation patterns of six tissues from six individuals were analyzed using the F-MSAP technique. Eight primer combinations (i.e., E-AAC/HM-TAC, E-AAC/HM-TCG, E-ACA/HM-TAG, E-ACA/HM-TGT, E-ACT/HM-TCG, E-ACT/HM-TTC, E-ACC/HM-TTC, and E-ACC/HMTGT) were selected to explore epigenetic information. A total of 10,203 fragments were detected, including 2,706, $2,855,1,118,1,264,1,138$, and 1,122 fragments in BAT, B, $\mathrm{H}, \mathrm{K}, \mathrm{L}$, and $\mathrm{M}$, respectively.

Genomic DNA methylation patterns and levels in six tissues of $\mathrm{R}$. ferrumequinum

Type II (hemi-methylation) and III (full-methylation) bands comprised $31.4 \% \quad(3,203 / 10,203)$ and $35.6 \%$ $(3,632 / 10,203)$ of the total fragments, respectively. Total methylated fragments accounted for $67.0 \%(6,835 / 10,203)$, and total methylation levels varied from $57.6 \%$ to $73.8 \%$ among tissues (Fig. 1). The levels of hemi-methylation were not significantly different among tissues, while significant differences in full-methylation patterns $(p<$ $0.001)$ and total methylation $(p=0.001)$ were detected (Fig. 1). The levels of full-methylation patterns and total methylation in BAT and B were higher than the other four tissues. When focusing on each methylation pattern of each tissue, the full-methylation levels of BAT and B were significantly higher than hemi-methylation $(p=0.005$ and $p$ $<0.001$, respectively). However, the opposite results were found for $\mathrm{H}(p=0.032)$ and $\mathrm{L}(p=0.014)$, indicating that 
hemi-methylation was the major methylation pattern in these two tissues, rather than full-methylation. Significant differences were not detected between the levels of the two methylation patterns in $\mathrm{K}$ and $\mathrm{M}$.

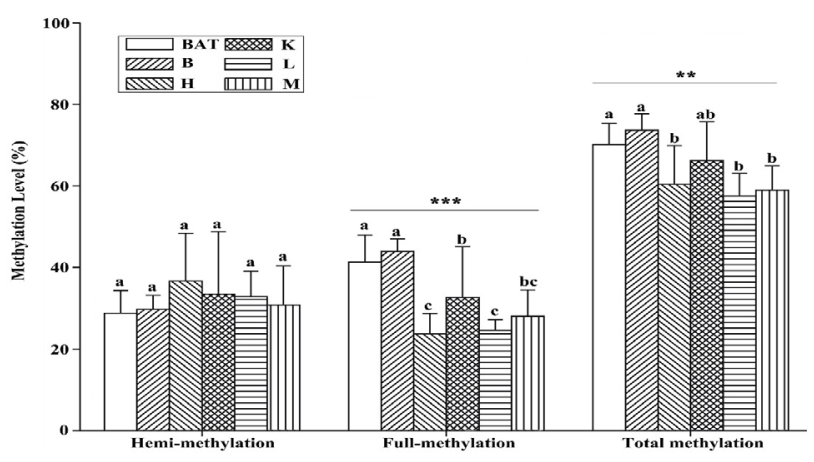

Fig. 1. Methylation levels in six tissues of $R$. ferrumequinum. Data are presented as the mean $\pm \mathrm{SE}$. Asterisks indicate significant differences: ${ }^{* *}, p<0.01 ; * * * p<0.001$.

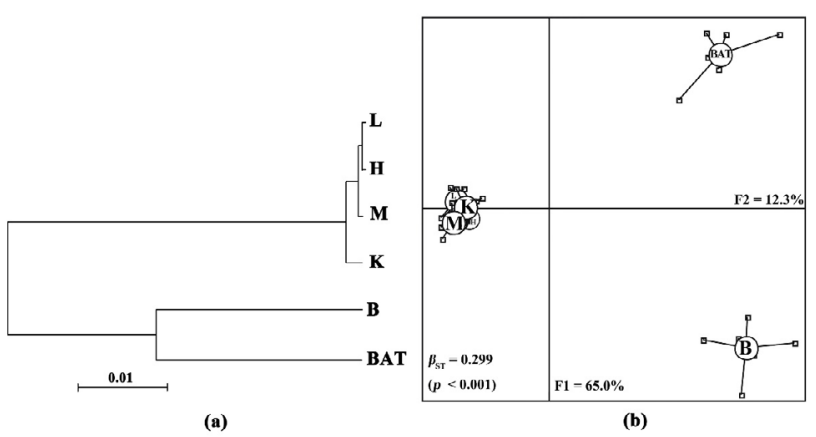

Fig. 2. Epigenetic differentiation among six $R$. ferrumequinum tissues. (a) Clustering tree based on Nei's unbiased epigenetic distance matrix. (b) Between-group eigen analysis using PCA values based on the epigenetic covariance matrix; the F1 and F2 axes explain $77.3 \%$ of the total variance $(p<0.001)$.

\section{Epigenetic differentiation among tissues}

Methylated loci and epigenetic distances were obtained to explore methylation differentiation among tissues. There were $44,32,59,16,15$, and 42 unique methylated loci in BAT, B, H, K, L and M, respectively (Table I). BAT had the largest number of unique hemi-methylation loci, but the smallest number of unique full-methylation loci. L and $\mathrm{M}$ had the smallest number of unique hemi-methylation loci, while $\mathrm{H}$ had the largest number of unique full-methylation loci. Compared to BAT and B, the tissues of $\mathrm{H}, \mathrm{K}, \mathrm{L}$, and $\mathrm{M}$ had the lowest epigenetic divergence (0.005-0.009) and clustered on one branch in the clustering tree based on Nei's unbiased distance matrix (Fig. 2a). Both B and BAT showed lower epigenetic divergence (0.025) and were obviously different from other tissues (0.064-0.092). The results of the multivariate analyses, which further explored the potential relationship among tissues based on methylated loci, supported the above results. However, B and BAT were significantly different $(p<0.001)$ (Fig. 2b).

Table I. Number of unique methylation loci in six $R$. ferrumequinum tissues.

\begin{tabular}{lll}
\hline Tissue & $\begin{array}{l}\text { Number of unique } \\
\text { hemi-methylation loci }\end{array}$ & $\begin{array}{l}\text { Number of unique } \\
\text { full-methylation loci }\end{array}$ \\
\hline BAT & 43 & 1 \\
B & 28 & 4 \\
H & 14 & 45 \\
K & 9 & 7 \\
L & 6 & 9 \\
M & 6 & 36 \\
\hline
\end{tabular}

\section{DISCUSSION}

DNA methylation regulates gene expression by binding MBDs and recruiting transcription repressors (i.e., HDACs) to repress transcription processes (Greenberg and Bourc'his, 2019), and thus, may play a vital role in tissue development and differentiation (Jones and Takai, 2001). Therefore, before further investigating the relationship between tissue-specific methylation and gene expression, the patterns and levels of DNA methylation in various tissues were explored first. In this study, the F-MSAP technique was used to explore the patterns and levels of methylation in six tissues of $R$. ferrumequinum.

It should be noted that the pattern and level of DNA methylation in the same tissue may vary seasonally. For example, Biggar and Storey (2014) observed a 1.7-fold increase in global DNA methylation of BAT tissue in hibernated 13-lined ground squirrels when compared to euthermic controls. Moreover, Weyrich et al. (2016) found that a temporary increase in ambient temperature induced methylation variation in the liver of male wild guinea pig (Cavia aperea), and these epigenetic modifications were transmitted to the F2 generation. Additionally, the age structure of free-living wild Bechstein's bats (Myotis bechsteinii) was established by DNA methylation of homologous genes (Wright et al., 2018). The results of these previous studies indicate that different physiological states of the body or environment (e.g., temperature) could affect methylation status. Considering these findings, greater horseshoe bats in a normal state (i.e., adult; no pregnancy, nursing, or hibernation) were selected for observation in this study. 
The genome-wide methylation levels in the six tissues of $R$. ferrumequinum were relatively high, ranging from $57.6 \%$ to $73.8 \%$ with an average of $67.0 \%$. These values were slightly higher than that of swine (Yang et al., 2011) and sika deer (Yang et al., 2018). Because Hpa II cleaves the hemi-methylated external Cs and Msp I cleaves full methylated internal $\mathrm{Cs}$ in 5'-CCGG-3' sites, the hemi-methylation and full-methylation pattern would be represented as $\mathrm{CHG}$ methylation and $\mathrm{CpG}$ methylation in this study, respectively. Significant differences were detected in the levels of full-methylation pattern among tissues, while there were no significant differences detected in the levels of hemi-methylation patterns among tissues. However, the levels of $\mathrm{CHG}$ methylation in each tissue were non-negligible. The existence and roles of non- $\mathrm{CpG}$ methylation have been ignored for a long time. In fact, non-CpG methylation occurs in embryonic tissues and stem cells (Ramsahoye et al., 2000) and may have higher frequencies in adult mammalian somatic cells (i.e., brain and skeletal muscle) (Pinney, 2014). Hao et al. (2016) found that there were similar $\mathrm{CpG}$ methylation proportions, but varying proportions in non- $\mathrm{CpG}$ methylation between control and heat-stressed pigs, indicating that non-CpG methylation was functionally involved in gene regulation (Pinney, 2014; Fuso, 2018; Fuso and Lucarelli, 2019). Notably, CHG methylation levels in H, K, L, and M tissues approached or exceeded corresponding $\mathrm{CpG}$ methylation levels, while BAT and B possessed a massive number of unique hemi-methylation loci. Thus, $\mathrm{CHG}$ methylation in each tissue may also play an important part in tissue development and differentiation of $R$. ferrumequinum.

The epigenetic differentiation among tissues, revealed by Nei's unbiased epigenetic distances and the multivariate analyses, indicated that $\mathrm{H}, \mathrm{K}, \mathrm{L}$, and $\mathrm{M}$ were more similar than B or BAT. B and BAT had different methylation profiles, which remains unclear and is worth investigating in the future. The differences among $\mathrm{H}, \mathrm{K}, \mathrm{L}$, and $\mathrm{M}$ were inconspicuous; however, the various methylation levels and diverse number of unique methylated loci indicate that there was considerable epigenetic differentiation among the four tissues, which may be related to gene expression during tissue development and differentiation (Yang et al., 2018).

\section{CONCLUSION}

In summary, the patterns and levels of methylation in six tissues of $R$. ferrumequinum in a normal state were explored using the F-MSAP technique in this study. There were relatively high methylation levels and both hemi-methylation and full-methylation exhibited major methylation patterns. The tissues levels of full-methylation and total methylation were significantly different and possessed a diverse number of unique methylated loci. A massive hemi-methylation bands existed, indicating that $\mathrm{CHG}$ methylation may play a potential role in tissue development and differentiation in greater horseshoe bats. BAT and B differed from other four tissues in DNA in fullmethylation and total methylation. This work provides basic data for future studies on the periodic variation of DNA methylation and intrinsic epigenetic mechanisms of vital biological processes in Chiropteran animals.

\section{ACKNOWLEDGMENT}

Our study was supported by the National Natural Science Foundation of China (grant no. 31870354, 31372214, 31400320), the Doctoral Foundation of Henan Polytechnic University (grant no. B2013-074), and Young Core Instructor Foundation of Henan Polytechnic University (grant no. No.2015-18). We would like to thank Xun Liu, Aoqiang Li, Zhongle Li and Guohong Xiao for their assistance with bat collection. We thank Let Pub (www.letpub.com) for its linguistic assistance during the preparation of this manuscript.

Statement of conflict of interest

The authors have declared no conflict of interest.

\section{REFERENCES}

Banlaki, Z., Cimarelli, G., Viranyi, Z., Kubinyi, E., Sasvari-Szekely, M. and Ronai, Z., 2017. DNA methylation patterns of behavior-related gene promoter regions dissect the gray wolf from domestic dog breeds. Mol. Genet. Genom., 292: 685-697. https://doi.org/10.1007/s00438-0171305-5

Biggar, Y. and Storey, K.B., 2014. Global DNA modifications suppress transcription in brown adipose tissue during hibernation. Cryobiology, 69: $\quad 333-338 . \quad$ https://doi.org/10.1016/j. cryobiol.2014.08.008

Bossdorf, O., Richards, C.L. and Pigliucci, M., 2008. Epigenetics for ecologists. Ecol. Lett., 11: 106-115.

Cedar, H. and Bergman, Y., 2012. Programming of DNA methylation patterns. Annu. Rev. Biochem., 81: 97-117. https://doi.org/10.1146/annurevbiochem-052610-091920

Fuso, A., 2018. Non-CpG methylation revised. Epigenomes, 2: 22. https://doi.org/10.3390/ epigenomes 2040022

Fuso, A. and Lucarelli, M., 2019. CpG and non$\mathrm{CpG}$ methylation in the diet-epigenetics- 
neurodegeneration connection. Curr. Nutr. Rep., 8: 74-82. https://doi.org/10.1007/s13668-019-0266-1

Greenberg, M.V.C. and Bourc'his, D., 2019. The diverse roles of DNA methylation in mammalian development and disease. Nat. Rev. mol. cell. Biol., 20: 590-607. https://doi.org/10.1038/s41580-0190159-6

Hao, Y., Cui, Y. and Gu, X., 2016. Genome-wide DNA methylation profiles changes associated with constant heat stress in pigs as measured by bisulfite sequencing. Sci. Rep., 6: 27507. https:// doi.org/10.1038/srep27507

Horvath, S. and Raj, K., 2018. DNA methylation-based biomarkers and the epigenetic clock theory of ageing. Nat. Rev. Genet., 19: 371-384. https://doi. org/10.1038/s41576-018-0004-3

$\mathrm{Hu}, \mathrm{J}$. and Barrett, R.D.H., 2017. Epigenetics in natural animal populations. J. evol. Biol., 30: 1612-1632. https://doi.org/10.1111/jeb.13130

Huang, X., Li, S., Ni, P., Gao, Y., Jiang, B., Zhou, Z. and Zhan, A., 2017. Rapid response to changing environments during biological invasions: DNA methylation perspectives. Mol. Ecol., 26: 66216633. https://doi.org/10.1111/mec.14382

Jones, G., Jacobs, D.S., Kunz, T.H., Willig, M.R. and Racey, P.A., 2009. Carpe noctem: The importance of bats as bioindicators. Endanger. Sp. Res., 8: 93115. https://doi.org/10.3354/esr00182

Jones, P.A., 2012. Functions of DNA methylation: Islands, start sites, gene bodies and beyond. Nat. Rev. Genet., 13: 484-492. https://doi.org/10.1038/ $\operatorname{nrg} 3230$

Jones, P.A. and Takai, D., 2001. The role of DNA methylation in mammalian epigenetics. Science, 293: 1068-1070. https://doi.org/10.1126/ science. 1063852

Klose, R.J. and Bird, A.P., 2006. Genomic DNA methylation: The mark and its mediators. Trends biochem. Sci., 31: 89-97. https://doi.org/10.1016/j. tibs.2005.12.008

Liu, S., Sun, K., Jiang, T., Ho, J.P., Liu, B. and Feng, J., 2012. Natural epigenetic variation in the female great roundleaf bat (Hipposideros armiger) populations. Mol. Genet. Genom., 287: 643-650 https://doi.org/10.1007/s00438-012-0704-X.

Lyko, F., 2018. The DNA methyltransferase family: A versatile toolkit for epigenetic regulation. Nat. Rev. Genet., 19: 81-92. https://doi.org/10.1038/ nrg. 2017.80

Michalak, E.M., Burr, M.L., Bannister, A.J. and Dawson, M.A., 2019. The roles of DNA, RNA and histone methylation in ageing and cancer. Nat. Rev. mol. cell. Biol., 20: 573-589. https://doi.org/10.1038/ s41580-019-0143-1

Morales-Nebreda, L., McLafferty, F.S. and Singer, B.D., 2019. DNA methylation as a transcriptional regulator of the immune system. Transl. Res., 204: 1-18. https://doi.org/10.1016/j.trsl.2018.08.001

Parisod, C. and Christin, P.A., 2008. Genome-wide association to fine-scale ecological heterogeneity within a continuous population of Biscutella laevigata (brassicaceae). New Phytol., 178: 436-447. https://doi.org/10.1111/j.1469-8137.2007.02361.x

Perez-Figueroa, A., 2013. Msap: A tool for the statistical analysis of methylation sensitive amplified polymorphism data. Mol. Ecol. Resour., 13: 522527. https://doi.org/10.1111/1755-0998.12064

Pinney, S.E., 2014. Mammalian non-cpg methylation: Stem cells and beyond. Biology, 3: 739-751. https:// doi.org/10.3390/biology3040739

Ramsahoye, B.H., Biniszkiewicz, D., Lyko, F., Clark, V., Bird, A.P. and Jaenisch, R., 2000. Non-CpG methylation is prevalent in embryonic stem cells and may be mediated by DNA methyltransferase 3a. Proc. natl. Acad. Sci., 97: 5237-5242. https:// doi.org/10.1073/pnas.97.10.5237

Reizel, Y., Sabag, O., Skversky, Y., Spiro, A., Steinberg, B., Bernstein, D., Wang, A., Kieckhaefer, J., Li, C., Pikarsky, E., Levin-Klein, R., Goren, A., Rajewsky, K., Kaestner, K.H. and Cedar, H., 2018. Postnatal DNA demethylation and its role in tissue maturation. Nat. Commun., 9: 2040. https://doi. org/10.1038/s41467-018-04456-6

Schrey, A.W., Alvarez, M., Foust, C.M., Kilvitis, H.J., Lee, J.D., Liebl, A.L., Martin, L.B., Richards, C.L. and Robertson, M., 2013. Ecological epigenetics: Beyond ms-aflp. Integr. Comp. Biol., 53: 340-350. https://doi.org/10.1093/icb/ict012

Schulz, B., Eckstein, R.L. and Durka, W., 2013. Scoring and analysis of methylation-sensitive amplification polymorphisms for epigenetic population studies. Mol. Ecol. Resour., 13: 642-653. https://doi. org/10.1111/1755-0998.12100

Schulze, K.V., Bhatt, A., Azamian, M.S., Sundgren, N.C., Zapata, G.E., Hernandez, P., Fox, K., Kaiser, J.R., Belmont, J.W. and Hanchard, N.A., 2019. Aberrant DNA methylation as a diagnostic biomarker of diabetic embryopathy. Genet. Med., 21: 2453-2461. https://doi.org/10.1038/s41436019-0516-z

Sevane, N., Martinez, R. and Bruford, M.W., 2019. Genome-wide differential DNA methylation in tropically adapted creole cattle and their iberian ancestors. Anim. Genet., 50: 15-26. https://doi. 
org/10.1111/age.12731

Smith, G., Smith, C., Kenny, J.G., Chaudhuri, R.R. and Ritchie, M.G., 2015. Genome-wide DNA methylation patterns in wild samples of two morphotypes of threespine stickleback (Gasterosteus aculeatus). Mol. Biol. Evol., 32: 888895. https://doi.org/10.1093/molbev/msu344

Song, F., Smith, J.F., Kimura, M.T., Morrow, A.D., Matsuyama, T., Nagase, H. and W.A., H., 2005. Association of tissue-specific differentially methylated regions (TDMs) with differential gene expression. Proc. natl. Acad. Sci., 102: 3336-3341. https://doi.org/10.1073/pnas.0408436102

Sun, Y., Hou, R., Fu, X., Sun, C., Wang, S., Wang, C., Li, N., Zhang, L. and Bao, Z., 2014. Genomewide analysis of DNA methylation in five tissues of zhikong scallop, Chlamys farreri. PLoS One, 9: e86232. https://doi.org/10.1371/journal. pone. 0086232

Thiebaut, F., Hemerly, A.S. and Ferreira, P.C.G., 2019. A role for epigenetic regulation in the adaptation and stress responses of non-model plants. Front. Pl. Sci., 10: 246. https://doi.org/10.3389/ fpls.2019.00246

Thioulouse, J., Chessel, D., Dole'dec, S. and Olivier, J.M., 1997. ADE-4: A multivariate analysis and graphical display software. Stat. Comput., 7: 75-83. https://doi.org/10.1023/A:1018513530268

Vos, P., Hogers, R., Bleeker, M., Reijans, M., Lee, T., Hornes, M., Friters, A., Pot, J., Paleman, J. and Kuiper, M., 1995. AFLP: A new technique for DNA fingerprinting. Nucl. Acids Res., 23: 4407-4414. https://doi.org/10.1093/nar/23.21.4407

Weyrich, A., Jeschek, M., Schrapers, K.T., Lenz, D., Chung, T.H., Rubensam, K., Yasar, S., Schneemann, M., Ortmann, S., Jewgenow, K. and Fickel, J., 2018. Diet changes alter paternally inherited epigenetic pattern in male wild guinea pigs. Environ. Epigenet., 4: dvy011. https://doi. org/10.1093/eep/dvy011

Weyrich, A., Lenz, D., Jeschek, M., Chung, T.H., Rubensam, K., Goritz, F., Jewgenow, K. and Fickel, J., 2016. Paternal intergenerational epigenetic response to heat exposure in male wild guinea pigs. Mol. Ecol., 25: 1729-1740. https://doi.org/10.1111/ mec. 13494

Wright, P.G.R., Mathews, F., Schofield, H., Morris, C., Burrage, J., Smith,A., Dempster, E.L. and Hamilton, P.B., 2018. Application of a novel molecular method to age free-living wild bechstein's bats. Mol. Ecol. Resour., 18: 1374-1380. https://doi. org/10.1111/1755-0998.12925

Xu, M.L., Li, X.Q. and Korban, S.S., 2000. AFLP-based detection of DNA methylation. Pl. mol. Biol. Rep., 18: 361-368. https://doi.org/10.1007/BF02825064

Yang, C., Zhang, M., Niu, W., Yang, R., Zhang, Y., Qiu, Z., Sun, B. and Zhao, Z., 2011. Analysis of DNA methylation in various swine tissues. PLoS One, 6: e16229. https://doi.org/10.1371/journal. pone.0016229

Yang, C., Zhang, Y., Liu, W., Lu, X. and Li, C., 2018. Genome-wide analysis of DNA methylation in five tissues of sika deer (Cervus nippon). Gene, 645 : 48-54. https://doi.org/10.1016/j.gene.2017.12.032 